\title{
Presynaptic nanodomains: a tale of two synapses
}

\author{
Lu-Yang Wang ${ }^{1,2}$ and George J. Augustine , $^{3,5,6}$ * \\ 1 Program in Neurosciences and Mental Health, SickKids Research Institute, Toronto, Canada \\ 2 Department of Physiology, University of Toronto, Toronto, Canada \\ ${ }^{3}$ Lee Kong Chian School of Medicine, Nanyang Technological University, Singapore, Singapore \\ ${ }^{4}$ Institute of Molecular and Cell Biology, Singapore, Singapore \\ ${ }^{5}$ Center for Functional Connectomics, Korea Institute of Science and Technology, Seoul, South Korea \\ ${ }^{6}$ Marine Biological Laboratory, Woods Hole, MA, USA
}

\section{Edited by:}

Hartmut Schmidt, University of

Leipzig, Germany

\section{Reviewed by:}

Manfred Heckmann, University of

Wuerzburg, Germany

Samuel Young, Max Planck Florida

Institute for Neuroscience, USA

\section{*Correspondence:}

George J. Augustine, Lee Kong

Chian School of Medicine, Nanyang

Technological University, 61 Biopolis

Drive, Proteos, Singapore 138673,

Singapore

e-mail: george.augustine@

ntu.edu.sg
Here we summarize the evidence from two "giant" presynaptic terminals-the squid giant synapse and the mammalian calyx of Held-supporting the involvement of nanodomain calcium signals in triggering of neurotransmitter release. At the squid synapse, there are three main lines of experimental evidence for nanodomain signaling. First, changing the size of the unitary calcium channel current by altering external calcium concentration causes a non-linear change in transmitter release, while changing the number of open channels by broadening the presynaptic action potential causes a linear change in release. Second, low-affinity calcium indicators, calcium chelators, and uncaging of calcium all suggest that presynaptic calcium concentrations are as high as hundreds of micromolar, which is more compatible with a nanodomain type of calcium signal. Finally, neurotransmitter release is much less affected by the slow calcium chelator, ethylene glycol tetraacetic acid (EGTA), in comparison to the rapid chelator 1,2-bis(oaminophenoxy)ethane- $N, N, N^{\prime}, N^{\prime}$-tetraacetic acid (BAPTA). Similarly, as the calyx of Held synapse matures, EGTA becomes less effective in attenuating transmitter release while the number of calcium channels required to trigger a single fusion event declines. This suggests a developmental transformation of microdomain to nanodomain coupling between calcium channels and transmitter release. Calcium imaging and uncaging experiments, in combination with simulations of calcium diffusion, indicate the peak calcium concentration seen by presynaptic calcium sensors reaches at least tens of micromolar at the calyx of Held. Taken together, data from these provide a compelling argument that nanodomain calcium signaling gates very rapid transmitter release.

Keywords: neurotransmitter release, calcium signaling, calcium channels, presynaptic terminals, synaptic vesicle trafficking

\section{INTRODUCTION TO THE CALCIUM DOMAIN CONCEPT}

The concept of local "domains" of intracellular calcium concentration developed from mathematical models of the diffusion of Ca ions $\left(\mathrm{Ca}^{2+}\right)$ away from the mouth of open calcium channels. The first published model, by Chad and Eckert (1984), laid out several key features of this concept. This paper proposed that opening of individual $\mathrm{Ca}^{2+}$ channels could form discrete spatial domains where $\mathrm{Ca}^{2+}$ concentration is very high locallywithin nanometers of a single open $\mathrm{Ca}^{2+}$ channel-but drops off steeply with distance away from the channel. In addition, increasingly large depolarizations of the membrane potential should have dual effects: increasing the number of such domains, by increasing the number of open $\mathrm{Ca}^{2+}$ channels, yet reducing the magnitude of the local $\mathrm{Ca}^{2+}$ concentration change within a domain because of the reduced unitary current through an open channel.

Simon and Llinás (1985) independently developed the $\mathrm{Ca}^{2+}$ domain concept and considered the possible role of such domains in triggering of neurotransmitter release from presynaptic terminals. In addition to confirming the deductions of Chad and Eckert (1984) regarding the basic properties of $\mathrm{Ca}^{2+}$ domains, they further concluded that these domains usually do not overlap appreciably for the case of squid presynaptic terminals. When many $\mathrm{Ca}^{2+}$ channels are opened by large, prolonged depolarizations, there can be a small degree of spatial overlap due to summation of $\mathrm{Ca}^{2+}$ from adjacent open channels. The modeling studies of Zucker and Fogelson (1986) reached a similar conclusion. Notably, Simon and Llinás (1985) concluded that an endogenous $\mathrm{Ca}^{2+}$ buffer could eliminate summation of $\mathrm{Ca}^{2+}$ signals associated with neighboring domains, but should have minimal effect on the peak $\mathrm{Ca}^{2+}$ concentration change occurring in the immediate vicinity of an open channel.

At its simplest, diffusion of $\mathrm{Ca}^{2+}$ from an open channel can be described by the following equation (Smith and Augustine, 1988):

$$
\left[\mathrm{Ca}^{2+}\right](x, t)=\frac{J_{C a}}{2 \pi D x} \operatorname{erfc} \frac{x}{2 \sqrt{D t}}
$$


Table 1 | "Rule of thumb" relationships for $\mathrm{Ca}^{2+}$ diffusion within domains.

\begin{tabular}{lcr}
\hline Distance & {$\left[\mathbf{C a}^{\mathbf{2 +}}\right](\sim \mathbf{1 / x})$} & Time $\left(\sim \boldsymbol{x}^{\mathbf{2}}\right)$ \\
\hline $10 \mathrm{~nm}$ & $100 \mu \mathrm{M}$ & $1 \mu \mathrm{sec}$ \\
$100 \mathrm{~nm}$ & $10 \mu \mathrm{M}$ & $100 \mu \mathrm{sec}$ \\
$1000 \mathrm{~nm}$ & $1 \mu \mathrm{M}$ & $10000 \mu \mathrm{sec}$ \\
\hline
\end{tabular}

where $x$ is distance from the channel, $t$ is time, $J_{C a}$ is the flux of $\mathrm{Ca}^{2+}$ through a single open channel, $D$ is the diffusion coefficient for $\mathrm{Ca}^{2+}$ and $e r f c$ is the complementary error function. This equation predicts that (1) while the channel is open, there will be an inverse relationship between $\mathrm{Ca}^{2+}$ concentration and distance from the channel; and (2) $\mathrm{Ca}^{2+}$ diffusion time will increase with the square of distance. To aid comprehension of these relationships, we provide "rule of thumb" $\mathrm{Ca}^{2+}$ diffusion parameters in Table 1. These parameters are to be taken as orderof-magnitude approximations because their precise values will depend on the value chosen for $D$, as well as the unitary current flowing through the open $\mathrm{Ca}^{2+}$ channel and the properties of cellular $\mathrm{Ca}^{2+}$ buffering. More complete mathematical treatments can be found elsewhere, for example in Smith and Augustine (1988), Naraghi and Neher (1997) and Neher (1998), as well as in the pioneering domain papers described above.

As mentioned above, it is possible that $\mathrm{Ca}^{2+}$ signals from adjacent open $\mathrm{Ca}^{2+}$ channels could overlap under some conditions. The degree of overlap leads to several qualitatively different forms of local $\mathrm{Ca}^{2+}$ signaling that are depicted in Figure 1. If there is no spatial overlap between the local $\mathrm{Ca}^{2+}$ domains, relative to the position of the relevant $\mathrm{Ca}^{2+}$ sensor, then a nanodomain occurs (Figure 1A). This type of signal is called a nanodomain because $\mathrm{Ca}^{2+}$ signaling will occur over dimensions of nanometers (Kasai, 1993; Schweizer et al., 1995; Augustine et al., 2003). If there is some degree of spatial overlap between neighboring domains and the $\mathrm{Ca}^{2+}$ sensor receives contributions from domains summing over a distance of approximately a micrometer, then this is microdomain-style $\mathrm{Ca}^{2+}$ signaling (Figure 1B). Finally, if the sensor receives $\mathrm{Ca}^{2+}$ ions diffusing over distances greater than a micrometer, due to summation of microdomains, then a radial gradient style of $\mathrm{Ca}^{2+}$ signaling is said to occur (Figure 1C). The differences in the spatial range of these different modes of $\mathrm{Ca}^{2+}$ signaling necessarily are associated with differences in the speed of $\mathrm{Ca}^{2+}$ triggering of biological processes, as indicated by the $t$-term in equation (1) and in the right column of Table 1.

From a physical perspective, there is no question that local domains of $\mathrm{Ca}^{2+}$ signaling occur in the immediate vicinity of an open $\mathrm{Ca}^{2+}$ channel. The question addressed in this review is how relevant such domain signaling is for release of neurotransmitters from presynaptic terminals. We will compare $\mathrm{Ca}^{2+}$ signaling at two presynaptic terminals whose large size makes them particularly amenable to experimental analysis: the squid giant synapse and the mammalian calyx of Held. From results obtained at these synapses, as well as selected results from other synapses, we will develop the argument that nanodomain $\mathrm{Ca}^{2+}$ signaling is prevalent at presynaptic terminals that rapidly release neurotransmitters, though microdomain signaling also has been established for some types of presynaptic terminals. Radial gradients are likely to be important only for presynaptic terminals that slowly release neuropeptides or for slower modulatory presynaptic actions of $\mathrm{Ca}^{2+}$ within fastacting synapses, for example $\mathrm{Ca}^{2+}$-dependent forms of synaptic plasticity.

\section{EVIDENCE FOR NANODOMAINS AT THE SOUID GIANT SYNAPSE}

Virtually all of the early experimental tests of the role of $\mathrm{Ca}^{2+}$ domains in triggering neurotransmitter release were performed at the squid giant synapse. As a result, work at this synapse established most of the experimental paradigms that have been used to probe local $\mathrm{Ca}^{2+}$ signaling in presynaptic terminals. In this section we will describe some of these key experiments.

The first clues regarding the possible role of presynaptic domain signaling came from analysis of the kinetics of transmitter release. The minimum synaptic delay between a presynaptic $\mathrm{Ca}^{2+}$ "tail" current (following a depolarization to a
A

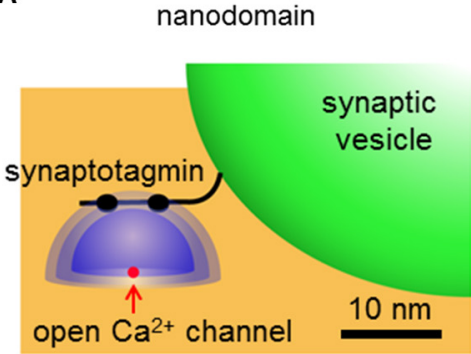

B

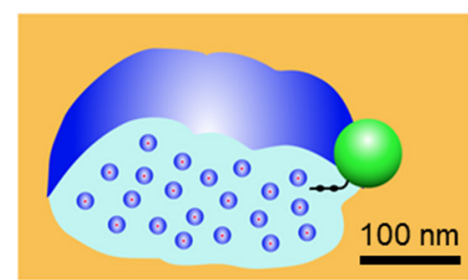

C

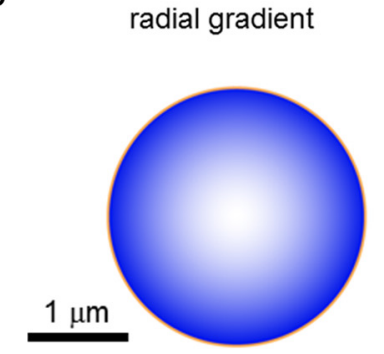

FIGURE 1 | Three types of local $\mathrm{Ca}^{2+}$ signaling. (A) Nanodomains arise from $\mathrm{Ca}^{2+}$ (blue) diffusing away from a single open $\mathrm{Ca}^{2+}$ channel (red) in the presynaptic plasma membrane (orange). The green spherical structure is a synaptic vesicle and a synaptotagmin-like $\mathrm{Ca}^{2+}$ sensor is shown protruding from the surface of the vesicle. (B) Microdomains arise from spatial overlap of local $\mathrm{Ca}^{2+}$ signals contributed by multiple open $\mathrm{Ca}^{2+}$ channels within a micrometer of each other. (C) Terminal-wide radial gradients of $\mathrm{Ca}^{2+}$ arise from long-distance diffusion of $\mathrm{Ca}^{2+}$ from channels at the plasma membrane. Derived from illustrations in Schweizer et al. (1995) and Augustine et al. (2003) 
very positive membrane potential) and the resultant postsynaptic response is very brief, on the order of hundreds of microseconds (Llinás et al., 1981; Augustine et al., 1985). Given the "rule of thumb" relationships for local $\mathrm{Ca}^{2+}$ signaling described above (Table 1), this indicates that $\mathrm{Ca}^{2+}$ must diffuse on the order of $100 \mathrm{~nm}$ or less before binding to the $\mathrm{Ca}^{2+}$ sensor for neurotransmitter release. This is consistent with a nanodomain type of presynaptic $\mathrm{Ca}^{2+}$ signal. Further, Simon and Llinás (1985) indicated that the relationship between presynaptic $\mathrm{Ca}^{2+}$ current and postsynaptic response could be explained by a model where domains do not overlap appreciably, i.e., nanodomain signaling.

While these initial observations provided indirect support for the role of nanodomain $\mathrm{Ca}^{2+}$ signals in triggering transmitter release at the squid giant synapse, they were open to alternative interpretations. However, several additional experiments have greatly bolstered acceptance of this notion. This experimental evidence can be grouped into three categories.

\section{MANIPULATIONS OF DOMAIN SIZE AND NUMBER}

Since the classic work of Dodge and Rahamimoff (1967), it has been known that $\mathrm{Ca}^{2+}$ acts "cooperatively", meaning that there is a high-order relationship between extracellular $\mathrm{Ca}^{2+}$ concentration and the amount of neurotransmitter release evoked by presynaptic action potentials. Cooperative triggering of transmitter release can be used as a tool to probe the spatial organization of presynaptic $\mathrm{Ca}^{2+}$ signaling.

Voltage clamp experiments at the squid giant synapse allowed the first direct measurement of $\mathrm{Ca}^{2+}$ entry into a presynaptic terminal and established that this cooperativity arises from a non-linear relationship between $\mathrm{Ca}^{2+}$ entry and the resultant release of neurotransmitters. Initially $\mathrm{Ca}^{2+}$ entry was varied by depolarizing the presynaptic membrane potential to different levels, thereby varying the number of open $\mathrm{Ca}^{2+}$ channels. While an initial account proposed a linear relationship between $\mathrm{Ca}^{2+}$ entry and transmitter release (Llinás et al., 1981), a follow-up study that optimized spatial control of presynaptic membrane potential indicated a third- or fourth-power relationship (Augustine et al., 1985). Because depolarizing to different membrane potentials changes the number of $\mathrm{Ca}^{2+}$ domains, as well as the $\mathrm{Ca}^{2+}$ concentration within each domain, these results are not easily interpreted in terms of local $\mathrm{Ca}^{2+}$ signals. A follow-up study by Augustine and Charlton (1986) circumvented this problem by depolarizing to a constant presynaptic membrane potential, to open a constant number of $\mathrm{Ca}^{2+}$ channels, while varying $\mathrm{Ca}^{2+}$ entry by changing external $\mathrm{Ca}^{2+}$ concentration. Under such conditions, an approximate fourthpower relationship between $\mathrm{Ca}^{2+}$ entry and transmitter release was observed (Figure 2A). Given that the number of $\mathrm{Ca}^{2+}$ domains will be constant under these conditions (Figure 2A insets), this result reveals that cooperativity occurs within the domains.

A strikingly different result is obtained when $\mathrm{Ca}^{2+}$ entry is varied by altering the duration of the presynaptic action potential. Blockade of potassium channels prolongs the duration of the presynaptic action potential and thereby increases $\mathrm{Ca}^{2+}$ entry into the terminal by increasing the number of
A Vary $\mathrm{Ca}^{2+}$ influx by varying external $\mathrm{Ca}^{2+}$

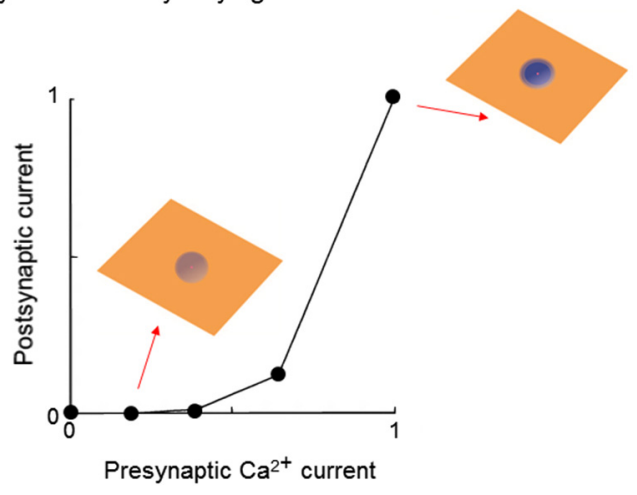

B

Vary $\mathrm{Ca}^{2+}$ influx by broadening action potential

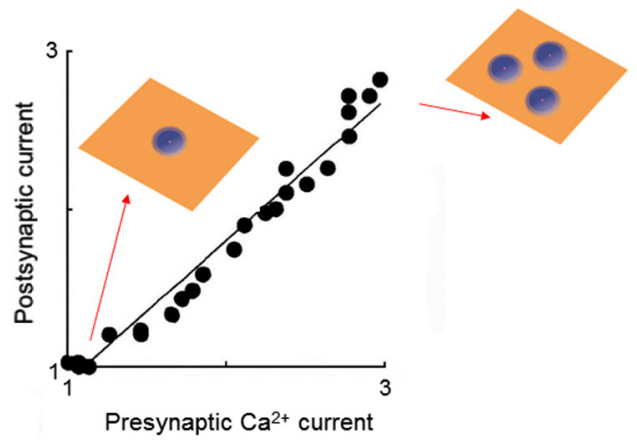

FIGURE 2 | Experimental strategies for probing local $\mathrm{Ca}^{2+}$ signaling during neurotransmitter release. (A) At a voltage-clamped squid giant synapse, varying external $\mathrm{Ca}^{2+}$ concentration changes presynaptic $\mathrm{Ca}^{2+}$ influx by keeping number of $\mathrm{Ca}^{2+}$ domains constant, while changing the amount of $\mathrm{Ca}^{2+}$ within each domain (insets). Under these conditions, the relationship between presynaptic $\mathrm{Ca}^{2+}$ current and amount of transmitter release, assessed by amplitude of the postsynaptic current, is a highly non-linear power function. Both presynaptic and postsynaptic responses are normalized to the maximum values measured at the highest external $\mathrm{Ca}^{2+}$ concentration. Data replotted from Augustine and Charlton (1986). (B) Pharmacologically broadening the presynaptic action potential at the squid giant synapse varies $\mathrm{Ca}^{2+}$ influx by opening additional $\mathrm{Ca}^{2+}$ channels, thereby increasing the number of $\mathrm{Ca}^{2+}$ domains (insets). Under these conditions, the relationship between presynaptic $\mathrm{Ca}^{2+}$ current and amount of transmitter release is a linear function. Both presynaptic and postsynaptic responses are normalized to the values measured under control conditions (narrowest presynaptic action potential). Data replotted from Augustine et al. (1991).

open $\mathrm{Ca}^{2+}$ channels (Klein and Kandel, 1980). Under such conditions, a linear relationship between action potential duration and postsynaptic response was observed (Augustine, 1990). Although $\mathrm{Ca}$ influx was not measured directly, the known gating properties of the squid presynaptic $\mathrm{Ca}^{2+}$ channels allowed calculation of the presynaptic $\mathrm{Ca}^{2+}$ current and indicated a linear relationship between action potential duration and $\mathrm{Ca}^{2+}$ current magnitude (Augustine, 1990). Thus, there is a linear relationship between $\mathrm{Ca}^{2+}$ current and transmitter release when $\mathrm{Ca}^{2+}$ influx is varied by changing the number of open $\mathrm{Ca}^{2+}$ channels (Figure 2B; Augustine et al., 1991). 


\section{A}

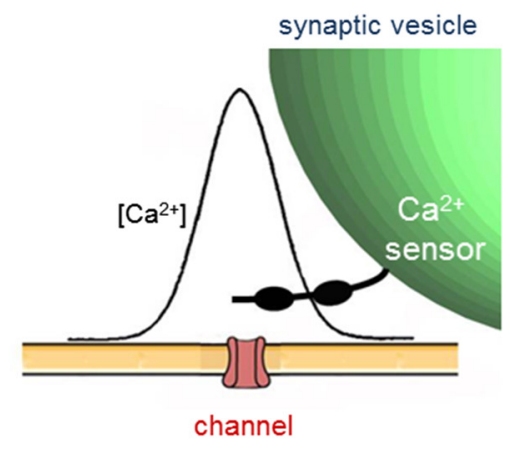

B

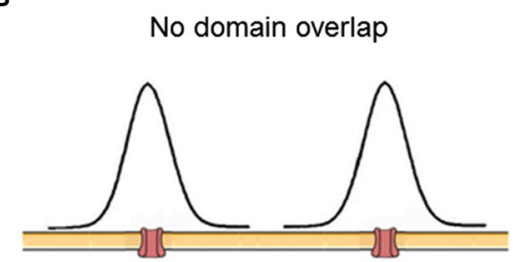

C

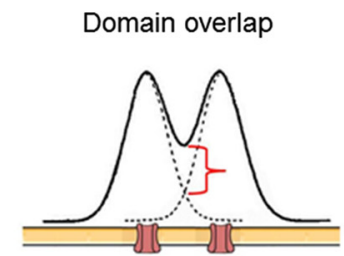

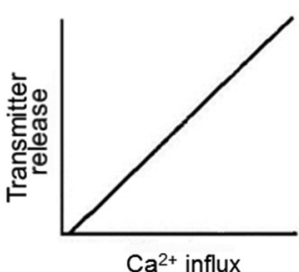

$\mathrm{Ca}^{2+}$ influx

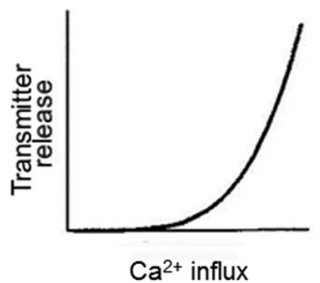

FIGURE 3 | Evaluating local $\mathrm{Ca}^{2+}$ signaling during broadening of presynaptic action potentials. (A) Diagram of spatial distribution of $\mathrm{Ca}^{2+}$ associated with a single open $\mathrm{Ca}^{2+}$ channel. (B) If open $\mathrm{Ca}^{2+}$ channels are sufficiently far apart, then $\mathrm{Ca}^{2+}$ signals associated with each channel will not overlap, creating a nanodomain arrangement (left). In this case, broader presynaptic action potentials will increase the number of discrete domains, leading to a proportional increase in transmitter release and a linear relationship between $\mathrm{Ca}^{2+}$ influx and release (right). (C) If open $\mathrm{Ca}^{2+}$ channels are close together, then $\mathrm{Ca}^{2+}$ signals associated with each channel will overlap, causing an increase in $\mathrm{Ca}^{2+}$ concentration (red bracket) within the local $\mathrm{Ca}^{2+}$ signal associated with each channel (left). This creates a microdomain $\mathrm{Ca}^{2+}$ signal. In this case, broader presynaptic action potentials will increase the $\mathrm{Ca}^{2+}$ concentration within each domain, leading to a supralinear increase in transmitter release due to the cooperative triggering of transmitter release by $\mathrm{Ca}^{2+}$. This spatial summation will yield a supralinear relationship between $\mathrm{Ca}^{2+}$ influx and release (right) when presynaptic action potentials are broadened. After Augustine et al. (1991).
Given that cooperativity occurs within a domain (Figure 2A), the fact that increasing the number of domains causes a linear increase in transmitter release (Figure 2B) leads to the conclusion that domains do not overlap during a presynaptic action potential. The logic behind this deduction is shown in Figure 3. In brief, if domains do not overlap then transmitter release will increase linearly according to the number of $\mathrm{Ca}^{2+}$ channels opened (Figures 3A,B). If domains overlap, then release will increase supralinearly due to summation of $\mathrm{Ca}^{2+}$ from neighboring domains, as well as the cooperative action of $\mathrm{Ca}^{2+}$ within a domain (Figure 3C). The results of Figure 2B are consistent with the expectations if domains do not overlap (Figure 3B, right). Thus, domains do not overlap during a presynaptic action potential at the squid giant synapse. Similar lines of experimentation have been used to probe the spatial dimensions of $\mathrm{Ca}^{2+}$ signaling in other presynaptic terminals (e.g., Wu and Saggau, 1994; Mintz et al., 1995).

\section{MEASUREMENTS OF LOCAL CALCIUM CONCENTRATION}

If the $\mathrm{Ca}^{2+}$ sensor for neurotransmitter release is located within nanometers of an open $\mathrm{Ca}^{2+}$ channel, as postulated by a nanodomain coupling scheme, then the local $\mathrm{Ca}^{2+}$ concentration experienced by this sensor should be in the range of tens to hundreds of micromolar (Table 1). Two types of experimental paradigms have tested this premise at the squid giant synapse.

The first experiment compared the ability of $\mathrm{Ca}^{2+}$ chelators of differing affinities to block transmitter release. For this purpose, analogs of the $\mathrm{Ca}^{2+}$ chelator 1,2-bis(o-aminophenoxy)ethane$\mathrm{N}, \mathrm{N}, \mathrm{N}$ 'N'-tetraacetic acid (BAPTA) were microinjected into the giant presynaptic terminal. A complex relationship between
$\mathrm{Ca}^{2+}$ affinity and chelator efficacy was observed: the most potent inhibitor of transmitter release was dibromoBAPTA, a chelator with intermediate $\mathrm{Ca}^{2+}$ affinity $(4.9 \mu \mathrm{M})$, while chelators with lower or higher affinities were less potent (Adler et al., 1991). A numerical model could predict such results only by assuming that the presynaptic $\mathrm{Ca}^{2+}$ sensor for transmitter release encounters $\mathrm{Ca}^{2+}$ levels on the order of $100 \mu \mathrm{M}$ or higher (Augustine et al., 1991). This prediction is consistent with the results of experiments employing photolysis of a caged $\mathrm{Ca}^{2+}$ chelator; even raising presynaptic $\mathrm{Ca}^{2+}$ concentration to $50 \mu \mathrm{M}$ produced rates of transmitter release lower than those evoked by a presynaptic action potential (Hsu et al., 1996). Together, these results are compatible with the predictions of a nanodomain coupling model.

The second experiment imaged presynaptic $\mathrm{Ca}^{2+}$ concentration during transmitter release. For this purpose, Llinás et al. (1992) used a version of the bioluminescent $\mathrm{Ca}^{2+}$-binding protein, aequorin, that was engineered to have an especially low affinity for $\mathrm{Ca}^{2+}$. This indicator protein, called n-Aequorin-J, only emits light at $\mathrm{Ca}^{2+}$ concentrations in the micromolar range or higher, with the amount of light emission increasing steeply as a function of $\mathrm{Ca}^{2+}$ concentration. Based on the amount of bioluminescence emitted by $n$-Aequorin-J injected into the squid giant presynaptic terminal, Llinás et al. (1992) concluded that presynaptic $\mathrm{Ca}^{2+}$ concentration reached 200-300 $\mu \mathrm{M}$ during transmitter release. Further, their measurements indicated that the regions of high $\mathrm{Ca}^{2+}$ concentration were quite localized, being a fraction of a square micrometer in area. While there are caveats regarding calibration of this indicator, as well as the spatial resolution of the $\mathrm{Ca}^{2+}$ imaging method, the results are compatible with the nanodomain coupling model. 
In sum, estimates provided by two complementary experimental approaches indicate that $\mathrm{Ca}^{2+}$ concentration rises on the order of hundreds of micromolar in the squid giant presynaptic terminal during transmitter release. Such results favor nanodomain coupling of $\mathrm{Ca}^{2+}$ channels to transmitter release at this synapse.

\section{DIFFERENTIAL EFFECTS OF CALCIUM CHELATORS}

The final experimental paradigm — and the one that has proven most useful for probing local $\mathrm{Ca}^{2+}$ signaling in presynaptic terminals - is based on comparison of $\mathrm{Ca}^{2+}$ chelators with different rates of $\mathrm{Ca}^{2+}$ binding (Adler et al., 1991). BAPTA binds $\mathrm{Ca}^{2+}$ very rapidly, with its on rate being diffusion-limited, while ethylene glycol tetraacetic acid (EGTA) binds $\mathrm{Ca}^{2+}$ more slowly because it is protonated at physiological $\mathrm{pH}$ and the bound proton must dissociate before $\mathrm{Ca}^{2+}$ can bind. This greatly slows the binding of $\mathrm{Ca}^{2+}$ to EGTA in comparison to BAPTA, even though the equilibrium affinity of these two chelators is roughly similar (Augustine et al., 1991). The slow binding of $\mathrm{Ca}^{2+}$ allows EGTA to serve as a high-pass temporal (and spatial) filter for $\mathrm{Ca}^{2+}$.

Neurotransmitter release evoked by presynaptic action potentials is completely inhibited when BAPTA is microinjected into the squid giant presynaptic terminal (Figure 4A). In contrast, neurotransmitter release is unaffected when EGTA is injected even at concentrations as high as $80 \mathrm{mM}$ (Figure 4B). Injection of EGTA is capable of buffering slower $\mathrm{Ca}^{2+}$ signaling processes, such as $\mathrm{Ca}^{2+}$ triggering of synaptic augmentation (Swandulla et al., 1991).

The interpretation of these results is that differences in the $\mathrm{Ca}^{2+}$ binding rates of these two chelators are responsible for their differential effects on neurotransmitter release. Thus, BAPTA can block transmitter release because it binds $\mathrm{Ca}^{2+}$ more rapidly than the $\mathrm{Ca}^{2+}$ sensor for transmitter release, while EGTA fails to block transmitter release because it binds $\mathrm{Ca}^{2+}$ slower than this sensor. Under conditions appropriate for the squid giant synapse, $80 \mathrm{mM}$ EGTA will bind $\mathrm{Ca}^{2+}$ with a time constant of approximately $50 \mu \mathrm{sec}$, while the same concentration of BAPTA requires only a fraction of a microsecond (Augustine et al., 1991). Thus, the $\mathrm{Ca}^{2+}$ sensor for transmitter release must bind $\mathrm{Ca}^{2+}$ in more than
$1 \mu \mathrm{sec}$ and in less than $50 \mu \mathrm{sec}$. Knowledge of this temporal constraint has been useful in establishing synaptotagmin as the $\mathrm{Ca}^{2+}$ sensor for transmitter release (Hui et al., 2005). In regard to the spatial dimensions of $\mathrm{Ca}^{2+}$ signaling during transmitter release, a time window of tens of microseconds means that $\mathrm{Ca}^{2+}$ diffuses no more than tens of nanometers prior to triggering transmitter release (Table 1). Thus, a process that is blocked by BAPTA but not by EGTA must be mediated by nanodomain $\mathrm{Ca}^{2+}$ signaling and this is the case for transmitter release at the squid giant synapse.

In summary, a variety of different experimental paradigms all point to the conclusion that transmitter release at the squid giant synapse is caused by nanodomain-style coupling of presynaptic $\mathrm{Ca}^{2+}$ channels to the presynaptic $\mathrm{Ca}^{2+}$ sensor, which presumably is synaptotagmin. In the next section we will see how these and other paradigms have been used to probe the spatial dimensions of presynaptic $\mathrm{Ca}^{2+}$ signaling at a different "giant" synapse, the mammalian calyx of Held.

\section{EVIDENCE FOR NANODOMAINS AT THE CALYX OF HELD SYNAPSE}

The giant calyx of Held synapse has been one of the most prominent preparations developed over the past two decades for analysis of synaptic transmission in the mammalian brain (Forsythe, 1994; Borst et al., 1995). Unfortunately, there is conflicting evidence about whether microdomain or nanodomain $\mathrm{Ca}^{2+}$ signaling mediates transmitter release at this synapse (Borst and Sakmann, 1996; Fedchyshyn and Wang, 2005). In this section we will survey this evidence and suggest that the conflict can be resolved by concluding that the spatial range of presynaptic $\mathrm{Ca}^{2+}$ signaling changes over the course of maturation of this synapse.

The calyx of Held synapse undergoes tremendous morphological remodeling in the course of its development, with its presynaptic terminal transforming from a spoon- or clublike structure with thin filopodia before the onset of hearing (P11-12) to a highly digitated structure with stalks and swellings containing a total of 500-800 active zones at maturity ( $>$ P16; Figure 5). Such structural transformations are

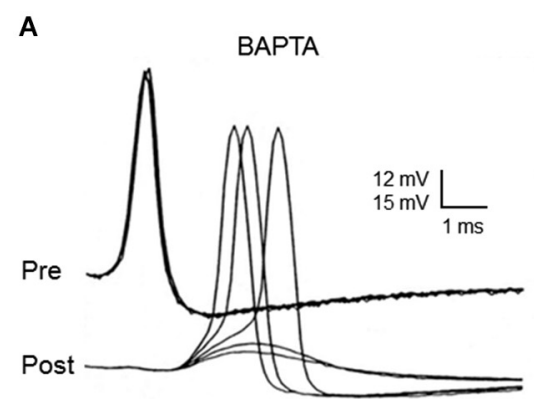

FIGURE 4 | Differential effects of EGTA and BAPTA on transmitter release at the squid giant synapse. While presynaptic microinjection of the rapid $\mathrm{Ca}^{2+}$ chelator, BAPTA, blocks transmitter release $(\mathbf{A})$, microinjection of the slower chelator, EGTA, has no effect. (B) Each family of traces shows five superimposed presynaptic action potentials
B

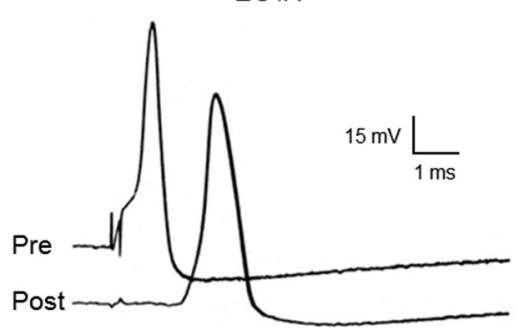

(Pre), as well as the postsynaptic responses (Post) that they evoke, during the course of chelator injection. While BAPTA reduces synaptic transmission to the point that postsynaptic responses are subthreshold, EGTA has no effect on postsynaptic response strength. Traces originally from Adler et al. (1991). 


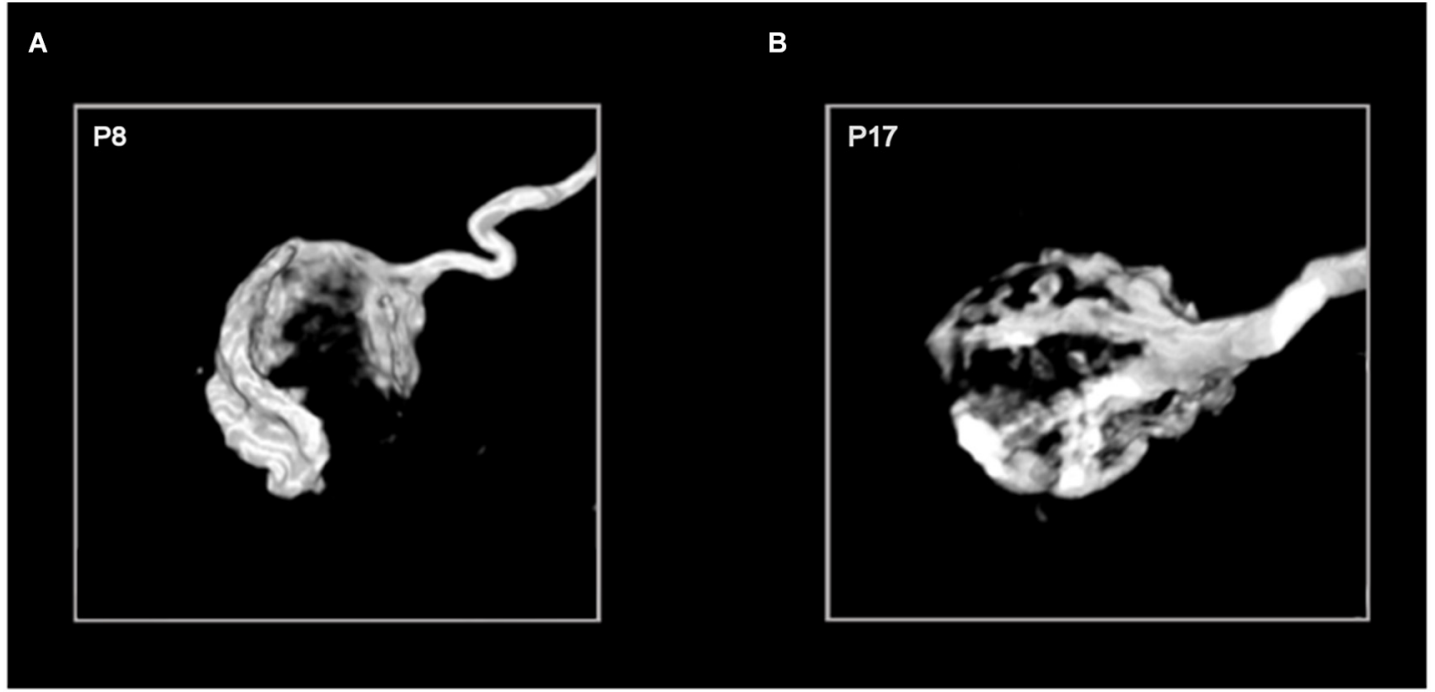

FIGURE 5 | Age-dependent morphological remodeling of the calyx of Held. Images of the 3-dimensional structure of P8 (A) and P17 (B) calyces filled with the fluorescent marker biotinylated dextran amine (courtesy of G. Grande). The diameter of each calyx sphere is approximately 15-20 micrometers.

thought to be important for supporting release and replenishment of synaptic vesicles (SVs), as well as facilitating clearance of neurotransmitter to alleviate postsynaptic receptor desensitization during high-frequency transmission (Trussell, 1999; von Gersdorff and Borst, 2002). In practice, calyces become less visible in brainstem slices for patch-clamping as myelination progresses during maturation, meaning that most early studies on the calyx of Held synapse focused on immature synapses (e.g., P8-11).

\section{EVIDENCE AGAINST NANODOMAIN COUPLING}

Using recordings of presynaptic $\mathrm{Ca}^{2+}$ currents $\left(I_{C a}\right)$ and excitatory postsynaptic currents $\left(I_{E P S C}\right)$ from young (P8-11) calyx of Held synapses, Borst and Sakmann (1996) first demonstrated that the amplitude of excitatory postsynaptic currents (EPSCs) follows the fourth power of presynaptic $\mathrm{Ca}^{2+}$ influx, similar to the squid giant synapse (Figure 2A). However, unlike the squid giant synapse, injection of EGTA at a concentration as low as $1 \mathrm{mM}$ attenuated EPSCs by about 50\%, leading to the conclusion that $\mathrm{Ca}^{2+}$ influx from many open channels (specifically $>60$ ) triggers fusion of a single synaptic vesicle. Furthermore, N-, $\mathrm{P} / \mathrm{Q}$, and R-type $\mathrm{Ca}^{2+}$ channels were found to jointly mediate transmitter release at this synapse, with $\mathrm{P} / \mathrm{Q}$-type $\mathrm{Ca}^{2+}$ channels being the most prominent subtype (Forsythe et al., 1998; Iwasaki and Takahashi, 1998; Wu et al., 1998, 1999). By photolysis of caged $\mathrm{Ca}^{2+}$ and computer simulations with $\mathrm{Ca}^{2+}$ buffer models (Bollmann et al., 2000; Schneggenburger and Neher, 2000), it was estimated that the peak $\mathrm{Ca}^{2+}$ concentration at $\mathrm{Ca}^{2+}$ sensors on SV is as low as $10 \mu \mathrm{M}$, an order of magnitude lower than that deduced for the squid giant synapse. These results are in striking contrast to what would be expected for nanodomain coupling, arguing in favor of a microdomain mode of $\mathrm{Ca}^{2+}$ signaling at the immature calyx of Held synapse (Meinrenken et al., 2002).

\section{EVIDENCE FOR NANODOMAIN COUPLING}

In parallel with morphological remodeling at the developing calyx of Held, presynaptic action potentials undergo a dramatic shortening in their duration (Taschenberger and von Gersdorff, 2000), which would reduce the number of activated $\mathrm{Ca}^{2+}$ channels and thereby attenuate $\mathrm{Ca}^{2+}$ influx. Given that the relationship between $I_{C a}$ and $I_{E P S C}$ is a power function

$$
I_{E P S C} \propto\left[I_{C a}\right]^{n}
$$

where $n$ denotes $\mathrm{Ca}^{2+}$ cooperativity (typically a value of 3-5; Augustine et al., 1985), spike narrowing would lead to a significant reduction in $I_{E P S C}$. In fact, quantal output is increased in older mice (Joshi and Wang, 2002) or maintained in rats (Iwasaki and Takahashi, 2001). This created a paradox: how could the fewer $\mathrm{Ca}^{2+}$ channels recruited by narrower action potentials during development somehow become more effective in triggering transmitter release (Yang and Wang, 2006; Kochubey et al., 2009; Leão and von Gersdorff, 2009)?

Two possible mechanisms have been considered: (1) the spatial coupling between open $\mathrm{Ca}^{2+}$ channels and $\mathrm{Ca}^{2+}$ sensors tightens to yield nanodomain signaling; and/or (2) the $\mathrm{Ca}^{2+}$ sensor (e.g., synaptotagmin) becomes more sensitive to $\mathrm{Ca}^{2+}$ to detect smaller rises in presynaptic $\mathrm{Ca}^{2+}$ concentration. To test the first possibility, Fedchyshyn and Wang (2005) injected EGTA (10 $\mathrm{mM}$ ) into developing calyx of Held synapses and found that while this slow $\mathrm{Ca}^{2+}$ buffer potently attenuates transmitter release in immature terminals ( $\mathrm{P} 8-12$ mice), as previously reported (Borst and Sakmann, 1996), EGTA had surprisingly little effect at mature synapses (P16-18). This indicates that the distance between $\mathrm{Ca}^{2+}$ channels and $\mathrm{Ca}^{2+}$ sensors shortens over the course of development. A similar conclusion was reached by using capacitance measurements of exocytosis under different $\mathrm{Ca}^{2+}$ buffering conditions (Leão and von Gersdorff, 2009). By using a depolarizing paradigm that recruits an increasing number 
of $\mathrm{Ca}^{2+}$ channels without changing the kinetics of $I_{\mathrm{Ca}}$ or the driving force for $\mathrm{Ca}^{2+}$, Fedchyshyn and Wang (2005) further demonstrated that $\mathrm{Ca}^{2+}$ cooperativity values ( $n$ ) were significantly higher in immature synapses than in mature synapses. Based on the logic depicted in Figure 3, this suggests that the number of $\mathrm{Ca}^{2+}$ channels required for triggering release of a synaptic vesicle decreases. It has also been shown that while transmitter release at $\mathrm{P} 8-12$ synapses requires both $\mathrm{N}$ and $\mathrm{P} / \mathrm{Q}$-type $\mathrm{Ca}^{2+}$ channels, only $\mathrm{P} / \mathrm{Q}$-type $\mathrm{Ca}^{2+}$ channels are involved at mature synapses. This suggests that nanodomains contain specific type of $\mathrm{Ca}^{2+}$ channels as part of their molecular architecture.

To test the second possibility, $\mathrm{Ca}^{2+}$ sensor sensitivity was measured in the developing calyx of Held synapse via simultaneous $\mathrm{Ca}^{2+}$ imaging and flash photolysis of caged $\mathrm{Ca}^{2+}$ chelators (Wang et al., 2008; Kochubey et al., 2009). Flash photolysis of caged $\mathrm{Ca}^{2+}$ has the advantage of bypassing $\mathrm{Ca}^{2+}$ entry through $\mathrm{Ca}^{2+}$ channels, instead directly triggering release by increasing intracellular $\mathrm{Ca}^{2+}$ concentration $\left(\left[\mathrm{Ca}^{2+}\right]_{i}\right)$ in a spatially homogeneous manner. Surprisingly, $\mathrm{Ca}^{2+}$ sensor sensitivity decreases over development (e.g., $K_{D}$ values rise from $\sim 80 \mu \mathrm{M}$ for P9-P11 vs. $\sim 120 \mu \mathrm{M}$ for P16-P19 synapses) while cooperativity ( $n$ ) remains the same. Taken together, these studies led to the conclusion that the spatial coupling between $\mathrm{Ca}^{2+}$ channels and $\mathrm{Ca}^{2+}$ sensors switches from microdomain to nanodomain signaling.
Such changes can account for the upregulation of transmitter release over the course of development of the calyx of Held synapse. Computer simulations with a linearized buffered $\mathrm{Ca}^{2+}$ diffusion model and a five-site kinetic model of transmitter release (Naraghi and Neher, 1997; Schneggenburger and Neher, 2000) deduced that during development the peak $\mathrm{Ca}^{2+}$ concentration seen by a $\mathrm{Ca}^{2+}$ sensor during an action potential increases from 35 to $56 \mu \mathrm{M}$ (Figures 6A,B). This is a consequence of tightened spatial coupling between $\mathrm{Ca}^{2+}$ channels and sensors; the modeling results indicate that the microdomain signaling during an action potential in immature synapses results from 12 $\mathrm{Ca}^{2+}$ channels with $50 \%$ open probability and $61 \mathrm{~nm}$ separation, while the nanodomain coupling at mature synapses results from $9 \mathrm{Ca}^{2+}$ channels with $35 \%$ open probability and $23 \mathrm{~nm}$ spacing (Figure 6C; Wang et al., 2008, 2009). This change in the spatial dimensions of presynaptic $\mathrm{Ca}^{2+}$ signaling nearly doubles the release rate and enables the peak of the local $\left[\mathrm{Ca}^{2+}\right]_{\mathrm{i}}$ transient to occur $\sim 410 \mu$ s earlier in mature synapses than in immature synapses (Figures 6A,B). Although direct evidence for the topographic organization of $\mathrm{Ca}^{2+}$ channels at the developing calyx remains elusive, these simulation results provide a theoretical framework for envisaging how a developmental transition from microdomain to nanodomain coupling can recapitulate a number of experimental observations, including an explanation for how narrower action potentials become more effective in
A

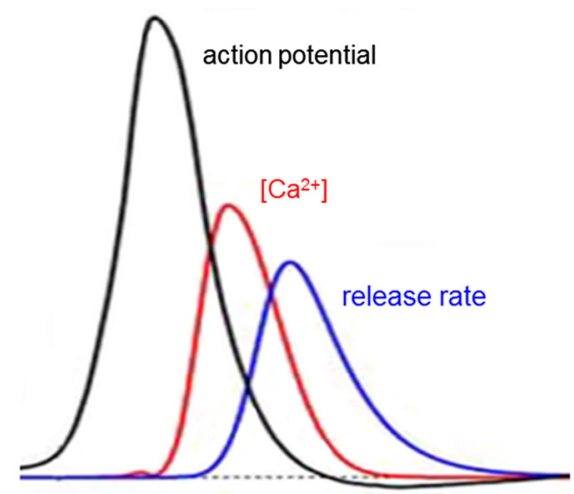

C

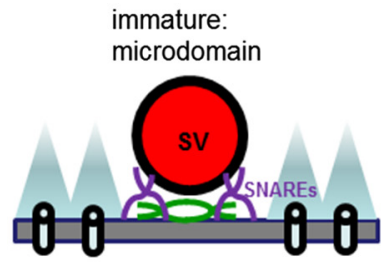

FIGURE 6 | Developmental change in presynaptic $\mathrm{Ca}^{2+}$ signaling at the calyx of Held synapse. $(\mathbf{A}, \mathbf{B})$ Developmental tightening of coupling between $\mathrm{Ca}^{2+}$ channels and synaptic vesicles boosts the local $\left[\mathrm{Ca}^{2+}\right]_{i}$ transient seen by the $\mathrm{Ca}^{2+}$ sensor (red traces) and the rate of transmitter release (blue traces) as action potentials (black traces) narrow (from Wang et al., 2008). (C) Transformation from microdomain to nanodomain coupling of $\mathrm{Ca}^{2+}$ channels
B

P16-19
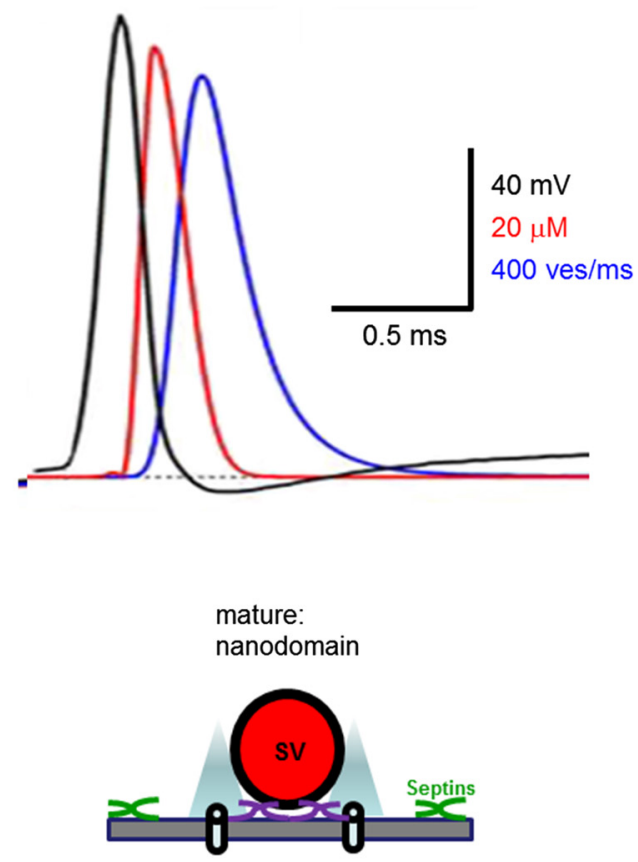

to transmitter release. Note that nanodomains are associated with shorter distance between $\mathrm{Ca}^{2+}$ channels and synaptic vesicles (SV) both in the plane of the presynaptic plasma membrane, as well as orthogonal to this membrane. This spatial reorganization of $\mathrm{Ca}^{2+}$ signaling is associated with translocation of septins (green) away from the active zone during development. 
triggering transmitter release (Taschenberger and von Gersdorff, 2000).

\section{EVIDENCE FOR NANODOMAIN COUPLING AT OTHER SYNAPSES}

The squid giant synapse and calyx of Held synapse are often considered to be specialized synapses because of their extraordinary size, speed and strength of synaptic transmission. Hence nanodomain coupling could be a feature unique to such highfidelity, excitatory "relay" synapses. However, this clearly is not the case because a number of synapses have now been shown to release neurotransmitters via nanodomain coupling.

In line with experiments suggesting nanodomain coupling of $\mathrm{Ca}^{2+}$ influx to transmitter release at the squid giant synapse and calyx of Held, early studies indicated that $\mathrm{Ca}^{2+}$ channels are tightly coupled to $\mathrm{Ca}^{2+}$ sensors to enable highly efficient transmission at neuromuscular synapses (Yoshikami et al., 1989; Delaney et al., 1991). In some cases, opening of a single $\mathrm{Ca}^{2+}$ channel is sufficient for triggering of fusion events at the active zones of chick ciliary ganglion synapses (Stanley, 1993; Gentile and Stanley, 2005).

Initial studies in mammalian synapses appeared to argue in favor of microdomain coupling (Luebke et al., 1993; Takahashi and Momiyama, 1993; Wheeler et al., 1994; Wu and Saggau, 1994; Mintz et al., 1995). These studies combined $\mathrm{Ca}^{2+}$ imaging in presynaptic terminals with patch-clamp recordings from postsynaptic neurons and treatment with subtype-specific $\mathrm{Ca}^{2+}$ channel blockers. The results collectively showed that not only are multiple $\mathrm{Ca}^{2+}$ channels involved in presynaptic $\mathrm{Ca}^{2+}$ signaling but also that different subtypes of $\mathrm{Ca}^{2+}$ channels can mediate transmitter release at a synapse, leading to the idea that opening of many adjacent $\mathrm{Ca}^{2+}$ channels forms microdomains.

It should be noted that the conditions employed in these different experiments differ in many ways. For example, the fraction of $\mathrm{Ca}^{2+}$ channels activated by an action potential differ, ranging from $\sim 10 \%$ at the squid giant synapse to $>70 \%$ at some mammalian central synapses. In addition, extracellular $\mathrm{Ca}^{2+}$ concentrations ranged from $11 \mathrm{mM}$ for the squid synapse to $1-2 \mathrm{mM}$ for mammalian central synapses and experimental temperatures varied from 15 to $37^{\circ} \mathrm{C}$. All of these variables profoundly influence the number of $\mathrm{Ca}^{2+}$ channels opened by an action potential, as well as the driving force on $\mathrm{Ca}^{2+}$ and the kinetics of $\mathrm{Ca}^{2+}$ diffusion within nerve terminals, thereby affecting the coupling of $\mathrm{Ca}^{2+}$ channels to transmitter release.

Under experimental conditions where these variables have been somewhat controlled and are comparable to conditions employed at the developing calyx of Held synapse, emerging evidence suggests that several conventional mammalian central synapses employ nanodomain $\mathrm{Ca}^{2+}$ signaling (Eggermann et al., 2011). For example, nanodomain $\mathrm{Ca}^{2+}$ signaling is found both at hippocampal basket cell-granule cell inhibitory synapses and at cerebellar parallel fiber-Purkinje cell excitatory synapses (Bucurenciu et al., 2008; Eggermann and Jonas, 2011; Schmidt et al., 2013). In addition, transmission at sensory synapses other than the calyx of Held apparently employ nanodomain coupling (Brandt et al., 2005; Jarsky et al., 2010). Together, results from a wide variety of mammalian synapses support the notion that nanodomain coupling is highly conserved and is therefore a general scheme for $\mathrm{Ca}^{2+}$ triggering of rapid neurotransmitter release.

\section{CONCLUSIONS}

We have highlighted key evidence from two giant synapses, the squid giant synapse and the calyx of Held synapse, that firmly establish nanodomains as the predominant mode of $\mathrm{Ca}^{2+}$ signaling that couples $\mathrm{Ca}^{2+}$ influx through presynaptic $\mathrm{Ca}^{2+}$ channels to vesicular fusion and synaptic transmission. There is no doubt that nanodomains exist at many synapses, but it is interesting to note that this mode of $\mathrm{Ca}^{2+}$ signaling appears to be primarily associated with synapses for fast-spiking neurons, where synaptic transmission is particularly important for preserving temporal precision of information flow (Yang et al., 2014). Nanodomains with tight $\mathrm{Ca}^{2+}$ signaling may be particularly suited to trigger highly synchronized fusion events with minimal synaptic delay, temporal jitter, or asynchronous transmitter release. The narrow action potentials typical of fast-spiking neurons are likely to produce brief $\mathrm{Ca}^{2+}$ signals with rapid rise and collapse of local $\left[\mathrm{Ca}^{2+}\right]$. Brief $\mathrm{Ca}^{2+}$ transients will also serve to prevent presynaptic $\mathrm{Ca}^{2+}$ overload and facilitate $\mathrm{Ca}^{2+}$ clearance during prolonged high-frequency transmission. On the other hand, microdomains with loose coupling between $\mathrm{Ca}^{2+}$ channels and $\mathrm{Ca}^{2+}$ sensors may allow a broader dynamic range for tuning quantal output at synapses where activity-dependent forms of synaptic plasticity play a key role in dynamically regulating synaptic efficacy (Vyleta and Jonas, 2014).

Given the dimensions of SV and active zones, it is reasonable to postulate that the nanodomain $\mathrm{Ca}^{2+}$ signaling requires specific molecular specializations to optimize physical interactions between $\mathrm{Ca}^{2+}$ channels and SV (Catterall and Few, 2008; Südhof, 2013). To advance our understanding of local $\mathrm{Ca}^{2+}$ signaling in presynaptic terminals, it will next be important to define the specific molecular specializations underlying both microdomain and nanodomain $\mathrm{Ca}^{2+}$ signaling, and how these two modes of $\mathrm{Ca}^{2+}$ signaling are regulated during development. Emerging evidence indicate that several presynaptic proteins help tether $\mathrm{Ca}^{2+}$ channels to SV; these proteins include RIM (Kiyonaka et al., 2007; Kaeser et al., 2011), Munc 13 (Chen et al., 2013), bassoon (Davydova et al., 2014) and even synaptotagmin (Young and Neher, 2009). Genetic deletion of the cytometrix protein Bruchpilot loosens the coupling of $\mathrm{Ca}^{2+}$ channels and sensors at Drosophila presynaptic terminals (Kittel et al., 2006). In contrast, knockout of septin 5, a filamentous protein that interacts with the SNARE proteins that mediate exocytosis, transforms microdomain coupling typical of immature synapses to nanodomain coupling with functional and morphological phenotypes nearly identical to mature calyces (Figure 6C; Yang et al., 2010). These results suggest that these two modes of local $\mathrm{Ca}^{2+}$ signaling are differentiated by specific molecular substrates and potentially could be inter-convertible to confer distinctive $\mathrm{Ca}^{2+}$ signaling properties to synapses.

\section{ACKNOWLEDGMENTS}

We thank Karen Chung for her help in preparing this paper. This work was supported by a CRP grant from the National Research 
Foundation of Singapore and by the World Class Institute (WCI) Program of the National Research Foundation of Korea (NRF) funded by the Ministry of Education, Science and Technology of Korea (MEST) (NRF Grant Number: WCI 2009-003) (to George J. Augustine), and by Operating Grants from the Canadian Institutes of Health Research (MOP-77610, MOP-81159, MOP-14692, VIH-105441) and Canada Research Chair (to Lu-Yang Wang).

\section{REFERENCES}

Adler, E. M., Augustine, G. J., Duffy, S. N., and Charlton, M. P. (1991). Alien intracellular calcium chelators attenuate neurotransmitter release at the squid giant synapse. J. Neurosci. 11, 1496-1507.

Augustine, G. J. (1990). Regulation of transmitter release at the squid giant synapse by presynaptic delayed rectifier potassium current. J. Physiol. 431, 343-364. doi: 10.1113/jphysiol.1990.sp018333

Augustine, G. J., Adler, E. M., and Charlton, M. P. (1991). The calcium signal for transmitter secretion from presynaptic nerve terminals. Ann. N Y Acad. Sci. 635, 365-381. doi: 10.1111/j.1749-6632.1991.tb36505.x

Augustine, G. J., and Charlton, M. P. (1986). Calcium dependence of presynaptic calcium current and post-synaptic response at the squid giant synapse. J. Physiol. 381, 619-640.

Augustine, G. J., Charlton, M. P., and Smith, S. J. (1985). Calcium entry and transmitter release at voltage-clamped nerve terminals of squid. J. Physiol. 367, $163-181$.

Augustine, G. J., Santamaria, F., and Tanaka, K. (2003). Local calcium signaling in neurons. Neuron 40, 331-346. doi: 10.1016/s0896-6273(03)00639-1

Bollmann, J. H., Sakmann, B., and Borst, J. G. (2000). Calcium sensitivity of glutamate release in a calyx-type terminal. Science 289, 953-957. doi: 10.1126/science. 289.5481 .953

Borst, J. G., Helmchen, F., and Sakmann, B. (1995). Pre- and postsynaptic wholecell recordings in the medial nucleus of the trapezoid body of the rat. J. Physiol. 489, 825-840. doi: 10.1113/jphysiol.1995.sp021095

Borst, J. G., and Sakmann, B. (1996). Calcium influx and transmitter release in a fast CNS synapse. Nature 383, 431-434. doi: 10.1038/383431a0

Brandt, A., Khimich, D., and Moser, T. (2005). Few CaV1.3 channels regulate the exocytosis of a synaptic vesicle at the hair cell ribbon synapse. J. Neurosci. 25, 11577-11585. doi: 10.1523/jneurosci.3411-05.2005

Bucurenciu, I., Kulik, A., Schwaller, B., Frotscher, M., and Jonas, P. (2008). Nanodomain coupling between $\mathrm{Ca}^{2+}$ channels and $\mathrm{Ca}^{2+}$ sensors promotes fast and efficient transmitter release at a cortical GABAergic synapse. Neuron 57, 536545. doi: 10.1016/j.neuron.2007.12.026

Catterall, W. A., and Few, A. P. (2008). Calcium channel regulation and presynaptic plasticity. Neuron 59, 882-901. doi: 10.1016/j.neuron.2008.09.005

Chad, J. E., and Eckert, R. (1984). Calcium domains associated with individual channels can account for anomalous voltage relations of Ca-dependent responses. Biophys. J. 45, 993-999. doi: 10.1016/s0006-3495(84)84244-7

Chen, Z., Cooper, B., Kalla, S., Varoqueaux, F., and Young, S. M. (2013). The Munc13 proteins differentially regulate readily releasable pool dynamics and calcium-dependent recovery at a central synapse. J. Neurosci. 33, 8336-8351. doi: 10.1523/jneurosci.5128-12.2013

Davydova, D., Marini, C., King, C., Klueva, J., Bischof, F., Romorini, S., et al. (2014). Bassoon specifically controls presynaptic P/Q-type $\mathrm{Ca}^{2+}$ channels via RIM-binding protein. Neuron 82, 181-194. doi: 10.1016/j.neuron.2014.02.012

Delaney, K., Tank, D. W., and Zucker, R. S. (1991). Presynaptic calcium and serotonin-mediated enhancement of transmitter release at crayfish neuromuscular junction. J. Neurosci. 11, 2631-2643.

Dodge, F. A. Jr., and Rahamimoff, R. (1967). Co-operative action a calcium ions in transmitter release at the neuromuscular junction. J. Physiol. 193, 419-432.

Eggermann, E., Bucurenciu, I., Goswami, S. P., and Jonas, P. (2011). Nanodomain coupling between $\mathrm{Ca}^{2+}$ channels and sensors of exocytosis at fast mammalian synapses. Nat. Rev. Neurosci. 13, 7-21. doi: 10.1038/nrn3125

Eggermann, E., and Jonas, P. (2011). How the 'slow' $\mathrm{Ca}^{2+}$ buffer parvalbumin affects transmitter release in nanodomain-coupling regimes. Nat. Neurosci. 15 , 20-22. doi: 10.1038/nn.3002

Fedchyshyn, M. J., and Wang, L. Y. (2005). Developmental transformation of the release modality at the calyx of Held synapse. J. Neurosci. 25, 4131-4140. doi: 10. 1523/jneurosci.0350-05.2005
Forsythe, I. D. (1994). Direct patch recording from identified presynaptic terminals mediating glutamatergic EPSCs in the rat CNS, in vitro. J. Physiol. 479, 381-387. doi: 10.1113/jphysiol.1994.sp020303

Forsythe, I. D., Tsujimoto, T., Barnes-Davies, M., Cuttle, M. F., and Takahashi, T. (1998). Inactivation of presynaptic calcium current contributes to synaptic depression at a fast central synapse. Neuron 20, 797-807. doi: 10.1016/s08966273(00)81017-x

Gentile, L., and Stanley, E. F. (2005). A unified model of presynaptic release site gating by calcium channel domains. Eur. J. Neurosci. 21, 278-282. doi: 10.1111/j. 1460-9568.2004.03841.x

Hsu, S. F., Augustine, G. J., and Jackson, M. B. (1996). Adaptation of $\mathrm{Ca}^{2+}$-triggered exocytosis in presynaptic terminals. Neuron 17, 501-512. doi: 10.1016/s08966273(00)80182-8

Hui, E., Bai, J., Wang, P., Sugimori, M., Llinas, R. R., and Chapman, E. R. (2005). Three distinct kinetic groupings of the synaptotagmin family: candidate sensors for rapid and delayed exocytosis. Proc. Natl. Acad. Sci. U S A 102, 5210-5214. doi: 10.1073/pnas.0500941102

Iwasaki, S., and Takahashi, T. (1998). Developmental changes in calcium channel types mediating synaptic transmission in rat auditory brainstem. J. Physiol. 509, 419-423. doi: 10.1111/j.1469-7793.1998.419bn.x

Iwasaki, S., and Takahashi, T. (2001). Developmental regulation of transmitter release at the calyx of Held in rat auditory brainstem. J. Physiol. 534, 861-871. doi: 10.1111/j.1469-7793.2001.00861.x

Jarsky, T., Tian, M., and Singer, J. H. (2010). Nanodomain control of exocytosis is responsible for the signaling capability of a retinal ribbon synapse. J. Neurosci. 30, 11885-11895. doi: 10.1523/jneurosci.1415-10.2010

Joshi, I., and Wang, L. Y. (2002). Developmental profiles of glutamate receptors and synaptic transmission at a single synapse in the mouse auditory brainstem. J. Physiol. 540, 861-873. doi: 10.1111/j.1469-7793.2002.00861.x

Kaeser, P. S., Deng, L., Wang, Y., Dulubova, I., Liu, X., Rizo, J., et al. (2011). RIM proteins tether $\mathrm{Ca}^{2+}$ channels to presynaptic active zones via a direct PDZdomain interaction. Cell 144, 282-295. doi: 10.1016/j.cell.2010.12.029

Kasai, H. (1993). Cytosolic $\mathrm{Ca}^{2+}$ gradients, $\mathrm{Ca}^{2+}$ binding proteins and synaptic plasticity. Neurosci. Res. 16, 1-7. doi: 10.1159/000154621

Kittel, R. J., Wichmann, C., Rasse, T. M., Fouquet, W., Schmidt, M., Schmid, A., et al. (2006). Bruchpilot promotes active zone assembly, $\mathrm{Ca}^{2+}$ channel clustering and vesicle release. Science 312, 1051-1054. doi: 10.1126/science.11 26308

Kiyonaka, S., Wakamori, M., Miki, T., Uriu, Y., Nonaka, M., Bito, H., et al. (2007). RIM1 confers sustained activity and neurotransmitter vesicle anchoring to presynaptic $\mathrm{Ca}^{2+}$ channels. Nat. Neurosci. 10, 691-701. doi: 10.1038/ nn 1904

Klein, M., and Kandel, E. R. (1980). Mechanism of calcium current modulation underlying presynaptic facilitation and behavioral sensitization in Aplysia. Proc. Natl. Acad. Sci. U S A 77, 6912-6916. doi: 10.1073/pnas.77.11. 6912

Kochubey, O., Han, Y., and Schneggenburger, R. (2009). Developmental regulation of the intracellular $\mathrm{Ca}^{2+}$ sensitivity of vesicle fusion and $\mathrm{Ca}^{2+}$-secretion coupling at the rat calyx of Held. J. Physiol. 587, 3009-3023. doi: 10.1113/jphysiol. 2009.172387

Leão, R. M., and von Gersdorff, H. (2009). Synaptic vesicle pool size, release probability and synaptic depression are sensitive to $\mathrm{Ca}^{2+}$ buffering capacity in the developing rat calyx of Held. Braz. J. Med. Biol. Res. 42, 94-104. doi: 10. 1590/s0100-879x2009000100014

Llinás, R., Steinberg, I. Z., and Walton, K. (1981). Relationship between presynaptic calcium current and postsynaptic potential in squid giant synapse. Biophys. J. 33, 323-351. doi: 10.1016/s0006-3495(81)84899-0

Llinás, R., Sugimori, M., and Silver, R. B. (1992). Microdomains of high calcium concentration in a presynaptic terminal. Science 256, 677-679. doi: 10. 1126/science. 1350109

Luebke, J. I., Dunlap, K., and Turner, T. J. (1993). Multiple calcium channel types control glutamatergic synaptic transmission in the hippocampus. Neuron 11 , 895-902. doi: 10.1016/0896-6273(93)90119-c

Meinrenken, C. J., Borst, J. G., and Sakmann, B. (2002). Calcium secretion coupling at calyx of held governed by nonuniform channel-vesicle topography. $J$. Neurosci. 22, 1648-1667.

Mintz, I. M., Sabatini, B. L., and Regehr, W. G. (1995). Calcium control of transmitter release at a cerebellar synapse. Neuron 15, 675-688. doi: 10.1016/08966273(95)90155-8 
Naraghi, M., and Neher, E. (1997). Linearized buffered $\mathrm{Ca}^{2+}$ diffusion in microdomains and its implications for calculation of $\left[\mathrm{Ca}^{2+}\right]$ at the mouth of a calcium channel. J. Neurosci. 15, 6961-6973.

Neher, E. (1998). Usefulness and limitations of linear approximations to the understanding of $\mathrm{Ca}^{2+}$ signals. Cell Calcium 24, 345-357. doi: 10.1016/s01434160(98)90058-6

Schmidt, H., Brachtendorf, S., Arendt, O., Hallermann, S., Ishiyama, S., Bornschein, G., et al. (2013). Nanodomain coupling at an excitatory cortical synapse. Curr. Biol. 23, 244-249. doi: 10.1016/j.cub.2012.12.007

Schneggenburger, R., and Neher, E. (2000). Intracellular calcium dependence of transmitter release rates at a fast central synapse. Nature 406, 889-893. doi: 10. $1038 / 35022702$

Schweizer, F. E., Betz, H., and Augustine, G. J. (1995). From vesicle docking to endocytosis: intermediate reactions of exocytosis. Neuron 14, 689-696. doi: 10. 1016/0896-6273(95)90213-9

Simon, S. M., and Llinás, R. R. (1985). Compartmentalization of the submembrane calcium activity during calcium influx and its significance in transmitter release. Biophys. J. 48, 485-498. doi: 10.1016/s0006-3495(85)83804-2

Smith, S. J., and Augustine, G. J. (1988). Calcium ions, active zones and synaptic transmitter release. Trends Neurosci. 11, 458-464. doi: 10.1016/01662236(88)90199-3

Stanley, E. F. (1993). Single calcium channels and acetylcholine release at a presynaptic nerve terminal. Neuron 11, 1007-1011. doi: 10.1016/08966273(93)90214-c

Südhof, T. C. (2013). Neurotransmitter release: the last millisecond in the life of a synaptic vesicle. Neuron 80, 675-690. doi: 10.1016/j.neuron.2013.10.022

Swandulla, D., Hans, M., Zipser, K., and Augustine, G. J. (1991). Role of residual calcium in synaptic depression and posttetanic potentiation: fast and slow calcium signaling in nerve terminals. Neuron 7, 915-926. doi: 10.1016/08966273(91)90337-y

Takahashi, T., and Momiyama, A. (1993). Different types of calcium channels mediate central synaptic transmission. Nature 366, 156-158. doi: 10.1038/36 $6156 \mathrm{a} 0$

Taschenberger, H., and von Gersdorff, H. (2000). Fine-tuning an auditory synapse for speed and fidelity: developmental changes in presynaptic waveform, EPSC kinetics and synaptic plasticity. J. Neurosci. 20, 9162-9173.

Trussell, L. O. (1999). Synaptic mechanisms for coding timing in auditory neurons. Annu. Rev. Physiol. 61, 477-496. doi: 10.1146/annurev.physiol.61.1.477

von Gersdorff, H., and Borst, J. G. (2002). Short-term plasticity at the calyx of held. Nat. Rev. Neurosci. 3, 53-64. doi: 10.1038/nrn705

Vyleta, N. P., and Jonas, P. (2014). Loose coupling between $\mathrm{Ca}^{2+}$ channels and release sensors at a plastic hippocampal synapse. Science 343, 665-670. doi: 10. 1126/science.1244811

Wang, L. Y., Fedchyshyn, M. J., and Yang, Y. M. (2009). Action potential evoked transmitter release in central synapses: insights from the developing calyx of Held. Mol. Brain 2:36. doi: 10.1186/1756-6606-2-36

Wang, L. Y., Neher, E., and Taschenberger, H. (2008). Synaptic vesicles in mature calyx of Held synapses sense higher nanodomain calcium concentrations during action potential-evoked glutamate release. J. Neurosci. 28, 14450-14458. doi: 10. 1523/jneurosci.4245-08.2008
Wheeler, D. B., Randall, A., and Tsien, R. W. (1994). Roles of N-type and Q-type $\mathrm{Ca}^{2+}$ channels in supporting hippocampal synaptic transmission. Science 264, 107-111. doi: 10.1126/science.7832825

Wu, L. G., Borst, J. G., and Sakmann, B. (1998). R-type $\mathrm{Ca}^{2+}$ currents evoke transmitter release at a rat central synapse. Proc. Natl. Acad. Sci. U S A 95, 47204725. doi: 10.1073/pnas.95.8.4720

Wu, L. G., and Saggau, P. (1994). Pharmacological identification of two types of presynaptic voltage-dependent calcium channels at CA3-CA1 synapses of the hippocampus. J. Neurosci. 14, 5613-5622.

Wu, L. G., Westenbroek, R. E., Borst, J. G., Catterall, W. A., and Sakmann, B. (1999). Calcium channel types with distinct presynaptic localization couple differentially to transmitter release in single calyx-type synapses. J. Neurosci. 19, 726-736.

Yang, Y. M., Fedchyshyn, M. J., Grande, G., Aitoubah, J., Tsang, C. W., Xie, H., et al. (2010). Septins regulate developmental switching from microdomain to nanodomain coupling of $\mathrm{Ca}^{2+}$ influx to neurotransmitter release at a central synapse. Neuron 67, 100-115. doi: 10.1016/j.neuron.2010.06.003

Yang, Y. M., and Wang, L. Y. (2006). Amplitude and kinetics of action potentialevoked $\mathrm{Ca}^{2+}$ current and its efficacy in triggering transmitter release at the developing calyx of held synapse. J. Neurosci. 26, 5698-5708. doi: 10. 1523/jneurosci.4889-05.2006

Yang, Y. M., Wang, W., Fedchyshyn, M. J., Zhou, Z., Ding, J., and Wang, L. Y. (2014). Enhancing the fidelity of neurotransmission by activity-dependent facilitation of presynaptic potassium currents. Nat. Commun. 5:4564. doi: 10 . 1038/ncomms5564

Yoshikami, D., Bagabaldo, Z., and Olivera, B. M. (1989). The inhibitory effects of omega-conotoxins on Ca channels and synapses. Ann. N Y Acad. Sci. 560, 230248. doi: 10.1111/j.1749-6632.1989.tb24100.x

Young, S. M., and Neher, E. (2009). Synaptotagmin has an essential function in synaptic vesicle positioning for synchronous release in addition to its role as a calcium sensor. Neuron 63, 482-496. doi: 10.1016/j.neuron.2009.07.028

Zucker, R. S., and Fogelson, A. L. (1986). Relationship between transmitter release and presynaptic calcium influx when calcium enters through discrete channels. Proc. Natl. Acad. Sci. U S A 83, 3032-3036. doi: 10.1073/pnas.83.9.3032

Conflict of Interest Statement: The authors declare that the research was conducted in the absence of any commercial or financial relationships that could be construed as a potential conflict of interest.

Received: 16 October 2014; paper pending published: 18 November 2014; accepted: 16 December 2014; published online: 26 January 2015.

Citation: Wang L-Y and Augustine GJ (2015) Presynaptic nanodomains: a tale of two synapses. Front. Cell. Neurosci. 8:455. doi: 10.3389/fncel.2014.00455

This article was submitted to the journal Frontiers in Cellular Neuroscience.

Copyright (c) 2015 Wang and Augustine. This is an open-access article distributed under the terms of the Creative Commons Attribution License (CC BY). The use, distribution and reproduction in other forums is permitted, provided the original author(s) or licensor are credited and that the original publication in this journal is cited, in accordance with accepted academic practice. No use, distribution or reproduction is permitted which does not comply with these terms. 